\title{
The Efficacy of Colloidal Oatmeal Cream I\% as Add-on Therapy in the Management of Chronic Irritant Hand Eczema: A Double-Blind Study
}

This article was published in the following Dove Press journal: Clinical, Cosmetic and Investigational Dermatology

\author{
Mohammadreza Sobhan (D) ' \\ Mahsa Hojati ${ }^{2}$ \\ Seyed-Yaser Vafaie (iD) ${ }^{3}$ \\ Davoud \\ Ahmadimoghaddam ${ }^{4}$ \\ Younes Mohammadi iD ${ }^{5}$ \\ Maryam Mehrpooya (iD) ${ }^{2}$
}

'Psoriasis Research Center, Department of Dermatology, Farshchian Hospital, Hamadan University of Medical Sciences, Hamadan, Iran; ${ }^{2}$ Department of Clinical Pharmacy, School of Pharmacy, Hamadan University of Medical Sciences, Hamadan, Iran; ${ }^{3}$ Department of Pharmaceutics, School of Pharmacy, Hamadan University of Medical Sciences, Hamadan, Iran; ${ }^{4}$ Department of Pharmacology and Toxicology, School of Pharmacy, Hamadan University of Medical Sciences, Hamadan, Iran; ${ }^{5}$ Modeling of Noncommunicable Diseases Research Center, School of Public Health, Hamadan University of Medical Sciences, Hamadan, Iran
Correspondence: Maryam Mehrpooya Department of Clinical Pharmacy, School of Pharmacy, Hamadan University of Medical Sciences, Shahid Fahmideh Ave, Hamadan 65I7838678, Iran

Tel +98813821868

$\mathrm{Fax}+98-8138381591$

Email m_mehrpooya2003@yahoo.com
Background: Irritant contact dermatitis (ICD) is the most frequent cause of hand eczema (HE). There is promising evidence with the use of topical oatmeal compounds in the management of inflammation- and itch-responses associated with diverse dermatologic conditions. This study aimed to evaluate the clinical benefit of colloidal oatmeal cream in the management of chronic irritant HE.

Methods: From October 2018 to November 2019, 79 patients with diagnosis of chronic irritant HE were allocated into either intervention or control groups by block randomization method. Besides fluocinolone $0.025 \%$ ointment for the first 2 weeks of treatment period, patients in the intervention and control groups were asked to use colloidal oatmeal $1 \%$ cream or base cream for additional 4 weeks as monotherapy. Changes in the HE severity based on the hand eczema severity index (HESCI) score, pruritus severity based on the visual analogue scale (VAS), and impact of skin disorder on patients quality of life based on the Dermatology Life Quality Index (DLQI) from baseline to weeks 2, 4, and 6 were assessed in the study groups.

Results: Fifty subjects, 26 in intervention and 24 in control, completed the course of the study. The results indicated, though relatively comparable decrease in mean HESI and VAS scores was observed in both groups by the end of week 2 , thereafter until end of the study a non-return of symptoms to baseline conditions was observed in the intervention group, while there was a significant return of symptoms to baseline conditions in the control group ( $p$ value $<0.001$ in both conditions). Further, a noticeable improvement in the DLQI score was seen in the intervention group compared with the control group ( $p$ value $<0.001$ ).

Conclusion: Findings demonstrate that colloidal oatmeal, a natural product with proven barrier protection, moisturization, anti-inflammatory, and soothing properties, can have ameliorative effects on eczema severity symptoms in patients with chronic irritant HE.

Keywords: hand eczema, irritant contact dermatitis, colloidal oatmeal, Hand Eczema Severity Index; Dermatology Life Quality Index

\section{Introduction}

Hand eczema (HE) is a very common and widespread skin condition, with a 1-year prevalence of $10 \%$ in the general population. It affects individuals of various occupations, but its prevalence is higher in some special occupational groups exposed to irritants or allergens, such as health-care workers, food handlers, and hairdressers. ${ }^{1}$ Chronic $\mathrm{HE}$ is a subset of $\mathrm{HE}$ which is characterized with a typical pattern of remission and exacerbation. The clinical signs and symptoms of $\mathrm{HE}$ include 
erythema, edema, vesiculation/blistering, hyperkeratosis, fissuration, pruritus, and pain. $\mathrm{HE}$ severity may range from mild involvement of a few fingers to a severe incapacitating and extremely itchy blistering eruption affecting all of the hand and fingers. ${ }^{2}$ Because hands are important organs of expression and communication, and are necessary for carrying out daily household and work-related activity, chronic HE can have a massive impact on patients' quality of life and ability to perform activities of daily living. ${ }^{3}$ Despite its high burden, the choice of treatments of HE by patients or their practitioners is still challenging.

Pathophysiology of HE is not precisely understood yet and likely it has multifactorial etiopathogenesis. A complex interplay between endogenous factors such as atopy and exogenous factors such as skin allergens or irritants implicate in the pathogenesis of chronic HE. ${ }^{4}$ Irritant contact dermatitis (ICD) is the most common cause of $\mathrm{HE}$ which is a localized inflammatory skin response to a wide range of chemical or physical agents. Major irritants are organic solvents, detergents, and water. In a vulnerable population, frequent and repeated exposure of the skin to irritants by inducing damage to epidermal cells and removing epidermal lipids from the stratum corneum results in a disruption of the barrier function of the skin. ${ }^{5}$ Impaired skin barrier function by increasing the risk of penetration of irritants through the skin induces local immunological and inflammatory reactions in the skin. Increased release of mediators and cytokines like tumor necrosis factor- $\alpha$ (TNF- $\alpha)$, interleukin (IL)-1, IL-6, IL-2, IL-8, c-interferon (IFN-c), and granulocyte monocyte-colony stimulating factor from keratinocytes has been observed in skin areas in response to irritant exposure. ${ }^{6,7}$

Besides patient education about avoidance of irritants and allergens and skin protection measures, topical antiinflammatory therapies such as corticosteroids are widely used as first-line therapy for HE. However, due to the development of tachyphylaxis as well as increased risk of multiple adverse events such as atrophy, telangiectasia, striae, acne, and other local adverse events and also systemic absorption in long-term use of topical corticosteroids, the introduction of steroid-sparing agents can be valuable. ${ }^{8}$ Colloidal oatmeal is a natural product that is derived from the whole dehulled grain. It has excellent safety record and is approved by FDA (US Food and Drug Administration) as an over-the-counter (OTC) skin protectant. ${ }^{9}$ Oatmeal possesses potent antioxidant and antiinflammatory properties that its clinical benefits in the treatment of a variety of inflammatory dermatologic disorders such as atopic dermatitis, psoriasis, and dry skin have been shown in the previous studies. ${ }^{10-12}$ The active ingredients in oatmeal consist of polysaccharides, proteins, lipids, saponins, enzymes, flavonoids, vitamins, and avenanthramides. Avenanthramides are phenolic compounds present in oats that mediate its anti-inflammatory activity. ${ }^{13}$ Decrease activation of nuclear factor kappa B (NF-kappa B) pathway in keratinocytes and diminish the secretion of the pro-inflammatory cytokines and histamine which are well-known key mechanisms in the pathophysiology of inflammatory dermatoses, are mechanisms that could contribute to the anti-inflammatory activity of colloidal oats on inflamed, dry, and itchy skin dermatoses. ${ }^{14}$ Additionally, it is thought that topical application of the colloidal oatmeal by promoting and restoring the skin's natural level of essential lipids such as ceramides, cholesterol, and free fatty acids can improve the repair of the skin barrier. ${ }^{15}$ Further, topical oatmeal by acting as a therapeutic moisturizer retains skin water content and prevents transepidermal water loss. ${ }^{16}$

Although the clinical benefits of topical colloidal oatmeal treatment are widely accepted in various dermatologic conditions, ${ }^{17}$ to our best knowledge, there is no clinical study that investigated its efficacy on the treatment HE. As such, the aim of this research was to evaluate the clinical benefit of colloidal oatmeal cream as an adjunctive treatment in combination with topical corticosteroids in the management of the chronic irritant HE.

\section{Materials and Methods}

We conducted a randomized, double-blind, placebocontrolled trial study with a 6-weeks follow up, from October 2018 to November 2019 in an outpatient dermatology clinic affiliated to Hamadan University of Medical Sciences, Hamadan, Iran. The study was conducted in accordance with the ethical principles of the Declaration of Helsinki and its later amendments. After obtaining the approvals by the Ethics Committees of Hamadan University of Medical Sciences (IR.UMSHA.REC.1397.398), the study was registered at the Iranian Registry of Clinical Trials (IRCT20120215009014N257). Information about the study was given to the participants and they gave written informed consent for study participation.

\section{Sample Size Estimation}

A sample size of 35 patients in each group was calculated based on the data of relevant clinical studies and expected changes of the hand eczema severity index (HESCI) score 
as a primary variable. A difference of 2 between two groups regarding the HESCI score, and a standard deviation of 2 was considered for sample size calculation (assuming study power equal to $90 \%, \alpha=0.05$, and $30 \%$ dropout rate).

\section{Participants and Randomization}

Patients were recruited in this study if the following inclusion criteria were met at baseline: patients age between 18 and 65 years old, clinical diagnosis of chronic irritant HE, moderate to severe severity of HE based on the HESCI score, lack of consuming any topical and systemic glucocorticoids during 4 weeks before the study, and lack of consuming any topical and systemic antipruritic treatments during 2 weeks before the study. Exclusion criteria at baseline and during the study were as follows: comorbid inflammatory diseases of skin such as psoriasis, pregnancy or lactation or expecting to get pregnant during the study, consuming any medicines other than prescribed medications during the study, presence of any adverse events that may lead to intolerance or any complications for patients, and poor adherence to the treatment. Diagnosis of chronic irritant $\mathrm{HE}$ has been made by an expert dermatologist based on history and clinical findings, performing skin biopsy examinations when specific disease entities were suspected, and exclusion of allergic contact dermatitis, atopic dermatitis, and other xerotic conditions.

One hundred and six patients with a diagnosis of irritant HE were assessed to enroll in this study. Of those, 17 patients did not agree to take part in the study and 26 patients did not meet the inclusion/exclusion criteria at baseline. The remaining 63 patients who met the study criteria and had interest in study participation were allocated into either intervention group (fluocinolone $0.025 \%$ ointment + colloidal oatmeal $1 \%$ cream, $\mathrm{N}=32$ ) or control group (fluocinolone $0.025 \%$ ointment + base cream, $\mathrm{N}=31$ ) by block randomization method (with four-patient blocks). The randomization was carried out by a statistician who was independent of the treatment. Additionally, both the study participants and the investigators were blinded to the treatment sequence throughout the study. Required demographic and clinical data of patients including age, sex, body mass index (BMI), and duration of HE were recorded for all study participants.

\section{Study Protocol}

Patients were required to discontinue any other topical and systemic preparations for 4 weeks before entering the study and during it. Patients were educated for minimizing their hand contact with irritants. All of the patients were asked to use fluocinolone $0.025 \%$ ointment (Najo Pharmaceutical Company, Tehran, Iran) twice daily for two weeks. Besides this treatment, patients in the intervention group were asked to use colloidal oatmeal $1 \%$ cream (Alvand Pharmed Pars Pharmaceutical Company, Hamadan, Iran) four times daily for 6 weeks (2-weeks in combination with fluocinolone $0.025 \%$ ointment and 4-weeks as monotherapy) and patients in the control group were asked to use base cream four times daily for same duration (2-weeks in combination with fluocinolone $0.025 \%$ ointment and 4-weeks as monotherapy). Adherence to treatment was determined by the quantity of the topical product left in the container at the end of each visit (weeks 2, 4, and 6 of the treatment).

\section{Study Endpoints}

The primary outcome was the change in clinical severity of HE from baseline to weeks 2, 4, and 6 after starting the treatment. The severity of chronic HE was determined by a single experienced dermatologist based on the HECSI score at baseline and at all subsequent study visits. HECSI is a physician-rated instrument for objective assessment of the severity of HE based on clinical symptoms. For scoring the severity of HE by HECSI, each hand was divided into five anatomical locations (fingertips, fingers (except the tips), palms, back of hands and wrists). The severity of the six clinical signs including erythema, induration $p a p u-$ lation, vesicles, fissuring, scaling and edema was graded in each of above-mentioned areas on the following scale: 0 , no skin changes; 1 , mild; 2 , moderate and 3 , severe. The extent of the involvement for each area (total of both hands) was given a score from 0 to $4(0,0 \% ; 1,1-25 \%$; $2,26-50 \% ; 3,51-75 \%$ and 4, 76-100\%). Finally, the HECSI score is obtained by multiplying the score of the extent of involvement for each area and the total sum of the intensity of each clinical feature which ranging from 0 to $360 .{ }^{16}$ The severity of $\mathrm{HE}$ according to the HECSI score at baseline and at different time points during the study were also categorized into clear, 0; almost clear, 1-16; moderate, 17-37; severe, 38-116; very severe, $\geq 117$ according to the Oosterhaven and Schuttelaar study. $^{18}$

As a secondary outcome, the severity of pruritus at baseline and weeks 2, 4, and 6 after starting the treatment also was questioned and recorded. Visual analogue scale (VAS) was used for scoring the severity of pruritus in the 
study patients. For this, a 10-cm horizontal line was used for self-assessment of the intensity of pruritus and patients were asked to rate the severity of their pruritus from 0 (no pruritus) to 10 (the most intensive pruritus they can imagine). Further, according to this scale, the severity of the pruritus was also categorized in three steps as follows: mild pruritus (VAS $<4.0$ ), moderate pruritus (VAS 4.0-7.0), and severe pruritus (VAS $>7.0){ }^{19}$

Impact of skin disorder on patients' quality of life as another secondary outcome was compared between two groups at baseline and the end of the study period (week 6). Persian version of Dermatology Life Quality Index (DLQI) was used for assessing patients' quality of life that its reliability and validity have been assessed in the Iranian population by Aghaei et al. ${ }^{20}$ DLQI is a 10 item self-reported questionnaire that assesses the impact of dermatological disease on different aspects of patient's quality of life over the last week. It subdivided into the following sub-domains: "symptoms and feelings, daily activities, leisure, work or school, personal relationships, and treatment". Each question is scored as "very much" (score 3), "a lot" (score 2), "a little" (score 1), and "not at all" (score 0 ). The total score is calculated by summing the score of each question and total scores range from a minimum of 0 to a maximum of 30 , with higher scores indicating greater impairment of the quality of life of the patient. $^{21}$

Any adverse event due to the therapy from the day of the first application of study treatment through the last follow-up visit was also recorded. To evaluate the adverse events of treatment, all patients were asked whether they had experienced one or more of the following possible adverse events including itching, burning, and erythema and exacerbation of them if such symptoms were present prior to the treatment. The type and severity (mild, moderate, or severe) of the adverse events were also recorded.

\section{Data Analysis}

Per protocol, analysis was exploited to analyze data of all individuals who completed the study. SPSS version 16.0 for windows (Chicago, IL, USA) was used for data analysis. The Kolmogorov-Smirnov test was used to assess the normal distribution of continuous variables. Normally- and non-normally distributed continuous data were expressed as mean (standard deviation: SD) and median (interquartile range: IQ), respectively. Categorical variables were reported as percentages. Mean (SD) and median (IQ) of continues variables were compared between the two groups using independent $t$-test and Mann-Whitney $U$-test, respectively. The distribution of categorical variables between two groups was compared using Chi-square or Fisher exact test (if more than $20 \%$ of the categories were expected to have frequencies less than 5). Moreover, to compare means of variables including mean pruritus score and mean HE severity score between two groups over time, as dependent variables, and control of their baseline differences, General Linear Model (GLM) ANOVA repeated measure was used to analyze data. Because of the deviation from the sphericity assumption, we used Greenhouse-Geisser correction to perform ANOVA results. P-value $<0.05$ was considered as the significant level.

\section{Results}

\section{Demographic and Baseline Characteristics}

A flow diagram of the progress through different phases of the study is shown in Figure 1. During the study period (from October 2018 to November 2019), 106 patients with a diagnosis of irritant HE were assessed for eligibility. Out of these patients, 63 patients fulfilled the inclusion/exclusion criteria and were randomized in a double-blind fashion into either control $(\mathrm{n}=31)$ or intervention $(\mathrm{n}=32)$ group. During the follow-up period, in the intervention group 6 patients (non-adherence to treatment: 2 patients, experiencing intolerable adverse events: 1 patient, and loss to follow-up: 3 patients) and in the control group, 7 patients (non-adherence to treatment: 4 patients, experiencing intolerable adverse events: 1 patient, and loss to followup: 2 patients) were excluded. No significant difference in the cause of patient loss during the follow-up period was noted between the two groups ( $\mathrm{p}=0.94)$. Finally, 24 out of 31 patients in the control group and 26 out of 32 patients in the intervention group completed the entire 6 weeks course of the study period. All of the following results were related to 50 individuals who completed the 6 weeks of the study.

The demographic and clinical characteristics of the patients are shown in Table 1. No statistically significant differences regarding demographic and clinical characteristics were noted between the two groups at baseline. Twenty-eight percent (14 patients) were male and $72 \%$ (36 patients) were female and the gender distribution was in favor of females in both groups $(75 \%$ and $69.2 \%$ in the control and intervention groups, respectively). The 
patients' age ranged from 18 to 56 years with the mean \pm SD age of $31.74 \pm 9.83$ years. The average duration of the disease was $31.75 \pm 26.50$ months in the control group and $37.73 \pm 47.96$ months in the intervention group. The two groups were similar in this regard, without a statistical difference $(\mathrm{P}=0.59)$.

\section{Efficacy Results}

The mean HESI score at baseline was $67.00 \pm 4.40$ in the control group (range 44-109), while it was $67.69 \pm 4.23$ in the intervention group (range 33-115). There was no significant difference between the two groups regarding the HESI score before treatment $(\mathrm{P}=0.91)$. The mean value of the VAS score at baseline was $5.92 \pm 0.26$ (range 3-9) in the intervention group and $5.63 \pm 0.27$ (range $3-8$ ) in the control group which showed no significant difference between the treatment groups. $(\mathrm{P}=0.42)$.

The general linear model analysis demonstrated a significant difference in the changes of HESI and VAS scores at different time points during the study between the two groups (P-value $<0.001$ in both conditions; Figure $2 \mathrm{~A}$ $\& 2 \mathrm{~B})$. The results indicated, although relatively comparable decrease in mean HESI and VAS scores was observed in both groups by the end of week 2 after starting treatment (2-weeks treatment period that fluocinolone $0.025 \%$ ointment was used in combination with colloidal oatmeal $1 \%$ cream or base cream), afterward the mean changes in HESI and VAS scores were significantly difference in the 2 groups with more favorable outcomes in the intervention group (Tables 2 and 3). As showed, after week 2 until end of the study (4-weeks treatment period that colloidal oatmeal $1 \%$ cream and base cream was used as monotherapy), non-return of symptoms to baseline conditions was observed in the intervention group, whereas a return of symptoms to baseline conditions in the control group was significant (Figure 2A, B and Tables 2 and 3).

The distribution of HE severity by 5-point categories of HESI score was similar in the two groups at beginning of the study and the patients in both groups had moderate to severe HE severity at baseline. Results regarding distribution analysis of HE severity at weeks 2, 4, and 6 showed that colloidal oatmeal $1 \%$ cream treated-patients shifted towards a better outcome than did base cream treated-patients (Table 4). Likewise, distribution analysis of pruritus severity by 3-point categories of VAS scores also demonstrated the superiority of the colloidal oatmeal cream application compared to the base cream application over time (Table 5).
Concerning impact of skin disorder on patients' quality of life, compared to the starting of the treatment at the end of the treatment period a noticeable improvement on the DLQI score was seen in the intervention group compared with the control group (the DLQI score decreased from $12.88 \pm 2.67$ at baseline to $5.58 \pm 5.35$ on week 6 after treatment in the patents receiving colloidal oatmeal cream and from $12.92 \pm 2.30$ to $10.92 \pm 3.78$ in the patients receiving base cream; $\mathrm{P}<0.001$; Table 6).

\section{Safety and Tolerability}

In respect of the occurrence of adverse events, in the control group, 3 patients experienced adverse events (one case reported burning and 2 cases reported itching) and in the intervention group, 4 patients experienced adverse events (two cases reported burning, one case reported erythema, and one case reported itching). Only, one patient in the intervention group and one patient in the control group quitted the study due to experiencing intolerable adverse events. None of the reported adverse events was serious or caused any complication for the patients. Therefore, it seems colloidal oatmeal $1 \%$ cream was well tolerated, demonstrating comparable safety to base cream.

\section{Discussion}

Based on our best knowledge, this is the first randomized, double-blind, control trial evaluating the efficacy of colloidal oatmeal cream in the treatment of irritant HE. The results of the current study showed that colloidal oatmeal cream as an adjunct therapy in patients with irritant HE can have ameliorative effects on eczema severity symptoms and eczema-related pruritus. In addition, while was well tolerated, treatment with colloidal oatmeal cream can improve patients' quality of life.

ICD is the most frequent cause of HE, arising primarily from contact with chemical or physical irritants. ${ }^{22}$ Exposure to exogenous irritating agents by direct cytotoxic skin damage leads to disruption of the epidermal barrier, the cytotoxic effect on keratinocytes, cytokine release from keratinocytes, activation of local immunological and inflammatory responses, and increased release of inflammatory mediators. ${ }^{23,24}$ Skin barrier disruption is the first step in the pathogenesis of ICD. Disruption of the epidermal barrier after exposure to irritants results in excessive water loss and increased penetration of irritants agents. ${ }^{25}$ Thus, skin barrier optimization is an effective therapeutic tool in the management of ICD. The beneficial effects of colloidal oatmeal application on skin barrier 


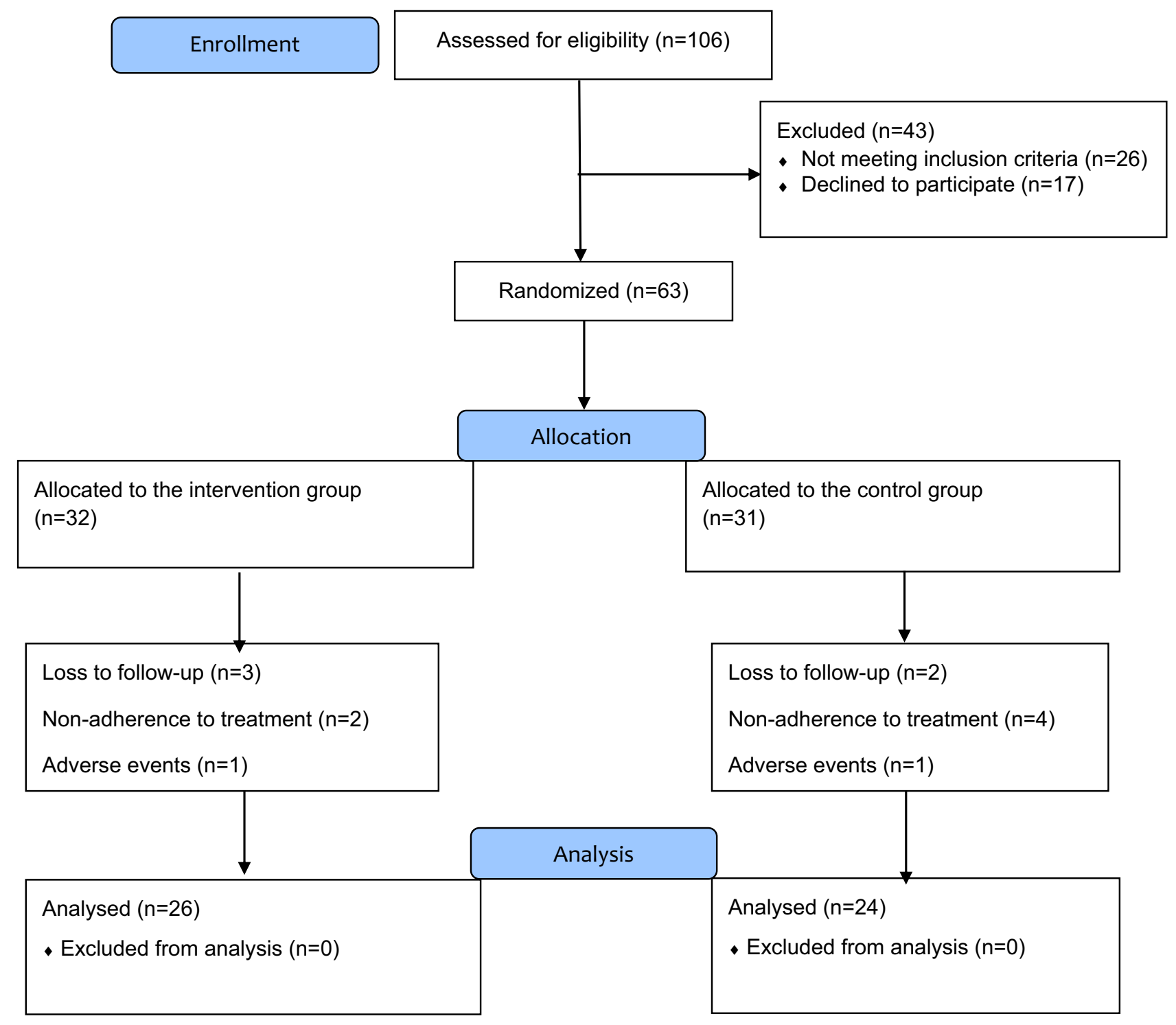

Figure I The flowchart of the study.

function have been reported in previous studies. In this regard, in one clinical study, oatmeal skin protectant lotion application was efficacious in improving moisturization and skin barrier function in female subjects with moderate to severely dry skin. ${ }^{26}$ The results of another study also showed that the oat-based moisturizer was as effective as the ceramide-based cream in improving trans-epidermal water loss (TEWL) and moisturization and even subjects treated with oat-based moisturizer showed significantly better performance after 1 and 2 weeks of treatment. ${ }^{27}$ In vitro model of dermatitis showed colloidal oatmeal through inducing the expression of genes related to epidermal differentiation and tight junctions, and lipid regulation can enhance recovery of skin barrier damage. ${ }^{28}$
Ceramides, cholesterol, and fatty acids are the major lipid species of the stratum corneum that act as a barrier to irritants, allergens, and microbes and limits skin water loss and regulates temperature. ${ }^{29}$ Common skin irritants such as Sodium Lauryl Sulfate (SLS) and sodium dodecyl sulfate (SDS) can reduce the content of ceramides in the stratum corneum. Examination of ceramide content following SLS application showed an inverse relationship between baseline ceramide weight and clinical irritation including erythema, scaling, dryness, and roughness. ${ }^{30}$ It seems that the high lipid components in oatmeal, especially omega-3 linoleic and omega- 6 linolenic acids play an important role in improving skin barrier function. ${ }^{31}$ Further, recently some research suggested oatmeal similar 
Table I Baseline Demographic and Clinical Characteristics of the Per Protocol Population

\begin{tabular}{|c|c|c|c|}
\hline \multirow[t]{2}{*}{ Variable } & \multicolumn{2}{|l|}{ Groups } & \multirow[t]{2}{*}{$P$ value } \\
\hline & $\begin{array}{l}\text { Control } \\
(\mathrm{N}=\mathbf{2 4})\end{array}$ & $\begin{array}{l}\text { Intervention } \\
(\mathrm{N}=\mathbf{2 6})\end{array}$ & \\
\hline Gender ( $N$; male/female) & $6 / 18$ & $8 / 18$ & 0.76 \\
\hline Age (years; mean \pm SD) & $\begin{array}{l}33.17 \pm \\
10.55\end{array}$ & $30.42 \pm 9.13$ & 0.33 \\
\hline BMI $\left(\mathrm{Kg} / \mathrm{m}^{2} ;\right.$ mean $\left.\pm \mathrm{SD}\right)$ & $\begin{array}{l}25.05 \pm \\
3.91\end{array}$ & $24.04 \pm 4.30$ & 0.40 \\
\hline $\begin{array}{l}\text { HE duration (months; } \\
\text { mean } \pm S D \text { ) }\end{array}$ & $\begin{array}{l}31.75 \pm \\
26.50\end{array}$ & $37.73 \pm 47.96$ & 0.59 \\
\hline $\begin{array}{l}\text { HECSI score at baseline } \\
\text { (mean } \pm S D)\end{array}$ & $\begin{array}{l}67.00 \pm \\
4.40\end{array}$ & $67.69 \pm 4.23$ & 0.91 \\
\hline $\begin{array}{l}\text { VAS score at baseline } \\
\text { (mean } \pm S D \text { ) }\end{array}$ & $5.63 \pm 0.27$ & $5.92 \pm 0.26$ & 0.42 \\
\hline
\end{tabular}

Abbreviations: eBMI, Body Mass Index; HE, hand czema; HECSI, hand eczema severity index; VAS, visual analogue scale.

to wheat and rice may be considered as a potential source of ceramides. ${ }^{32}$ Based on results of experimental research, oat lipid extracts also via the activation of peroxisome proliferator-activated receptor (PPAR) pathways can induce ceramide synthesis in keratinocytes and consequently enhance skin barrier repair. ${ }^{33}$

Healthy skin typically has acidic $\mathrm{pH}$, ranging between 4.6 and 5.6 that help in the production of ceramide and lipid by the $\mathrm{pH}$-dependent enzymes. ${ }^{34}$ Repeated exposure to alkaline substances such as soap, bleach, solvents, and even tap water can disturb $\mathrm{pH}$ balance and consequently disrupt the epidermal barrier. ${ }^{5}$ Thus, preventing an alkaline $\mathrm{pH}$ shift in the skin can enhance barrier homeostasis and prevent skin irritation. Preliminary in vitro evidence has shown that the ingredients in oatmeal, such as saponins can act as a buffer system, restoring the normal $\mathrm{PH}$ of the

Table 2 Comparison of Eczema Severity Based on the HECSI Tool Between 2 Groups at Different Time Points During the Study (as Mean \pm SD)

\begin{tabular}{|l|l|l|l|}
\hline \multirow{2}{*}{$\begin{array}{l}\text { HECSI } \\
\text { Score }\end{array}$} & \multicolumn{2}{|l|}{ Groups } & \multirow{2}{*}{ P-value } \\
\cline { 2 - 3 } & $\begin{array}{l}\text { Control } \\
(\mathbf{N}=\mathbf{2 4 )}\end{array}$ & $\begin{array}{l}\text { Intervention } \\
\mathbf{( N = 2 6 )}\end{array}$ & \\
\hline Baseline & $67.00 \pm 4.40$ & $67.69 \pm 4.23$ & 0.91 \\
Week 2 & $35.79 \pm 2.38$ & $28.77 \pm 3.50$ & 0.03 \\
Week 4 & $44.83 \pm 4.58$ & $25.80 \pm 4.39$ & 0.004 \\
Week 6 & $54.13 \pm 6.42$ & $23.73 \pm 6.17$ & 0.001 \\
\hline
\end{tabular}

Abbreviation: HECSI, hand eczema severity index.
Table 3 Comparison of Pruritus Severity Based on the VAS Scale Between 2 Groups at Different Time Points During the Study (as Mean \pm SD)

\begin{tabular}{|c|c|c|c|}
\hline \multirow{2}{*}{$\begin{array}{l}\text { VAS } \\
\text { Score }\end{array}$} & \multicolumn{2}{|l|}{ Groups } & \multirow[t]{2}{*}{ P-value } \\
\hline & $\begin{array}{l}\text { Control } \\
(\mathrm{N}=24)\end{array}$ & $\begin{array}{l}\text { Intervention } \\
(\mathbf{N}=\mathbf{2 6})\end{array}$ & \\
\hline Baseline & $5.63 \pm 0.27$ & $5.92 \pm 0.26$ & 0.42 \\
\hline Week 2 & $2.46 \pm 0.32$ & $1.62 \pm 0.31$ & 0.06 \\
\hline Week 4 & $3.75 \pm 0.34$ & $1.65 \pm 0.32$ & $<0.001$ \\
\hline Week 6 & $4.66 \pm 0.43$ & $1.50 \pm 0.42$ & $<0.001$ \\
\hline
\end{tabular}

Abbreviation: VAS, visual analogue scale.

skin and through it can enhance recovery of barrier damage in skin dermatitis. ${ }^{28}$

Activation of the epidermal keratinocytes and subsequent release of pro-inflammatory cytokines, such as interleukin (IL)-1 $\alpha$, IL-1 $\beta$, IL-6, and tumor necrosis factor (TNF)- $\alpha$ is another key pathogenic factor in acute-phase reactions of ICD. Releasing these cytokines can stimulate further production of other proinflammatory biomarkers that enhance the delivery of immune cells into the irritant injury site and exacerbate skin inflammation. ${ }^{35}$ Considering the important role of inflammation in the pathogenesis of ICD, in cases that barrier repair alone is insufficient to restore the skin barrier, anti-inflammatory agents like topical corticosteroids are used for extending the effectiveness of moisturizers and skin barrier treatments. ${ }^{36-38}$ However, due to concerns regarding the development of both local and systemic adverse events in the long-term use of topical corticosteroids, ${ }^{39}$ every attempt should be made to avoid the use of topical corticosteroids wherever possible. Thus, reducing inflammation with steroid-sparing moisturizers is a valuable therapeutic modality in the management of ICD. Colloidal oatmeal is one of the topical compounds that due to its potent anti-oxidant and anti-inflammatory properties may allow for reduced use of corticosteroids. From the biological point of view, colloidal oatmeal is a rich source of different types of phenols that are responsible for its inflammatory effects. Avenanthramides are the main polyphenolic compounds in oats that exhibit antioxidant and anti-inflammatory effects in a dosedependent manner. ${ }^{40,41}$ Anti-inflammatory and antioxidant activity of oatmeal extract may be attributed to its capacity to inhibit NF- $\kappa$ B release from keratinocytes which has a key role in the activation of pro-inflammatory and oxidative pathways. ${ }^{11,42}$ In vitro models of inflammatory dermatological conditions, treatment of TNF- $\alpha$ stimulated human keratinocytes with avenanthramides significantly decreased the 

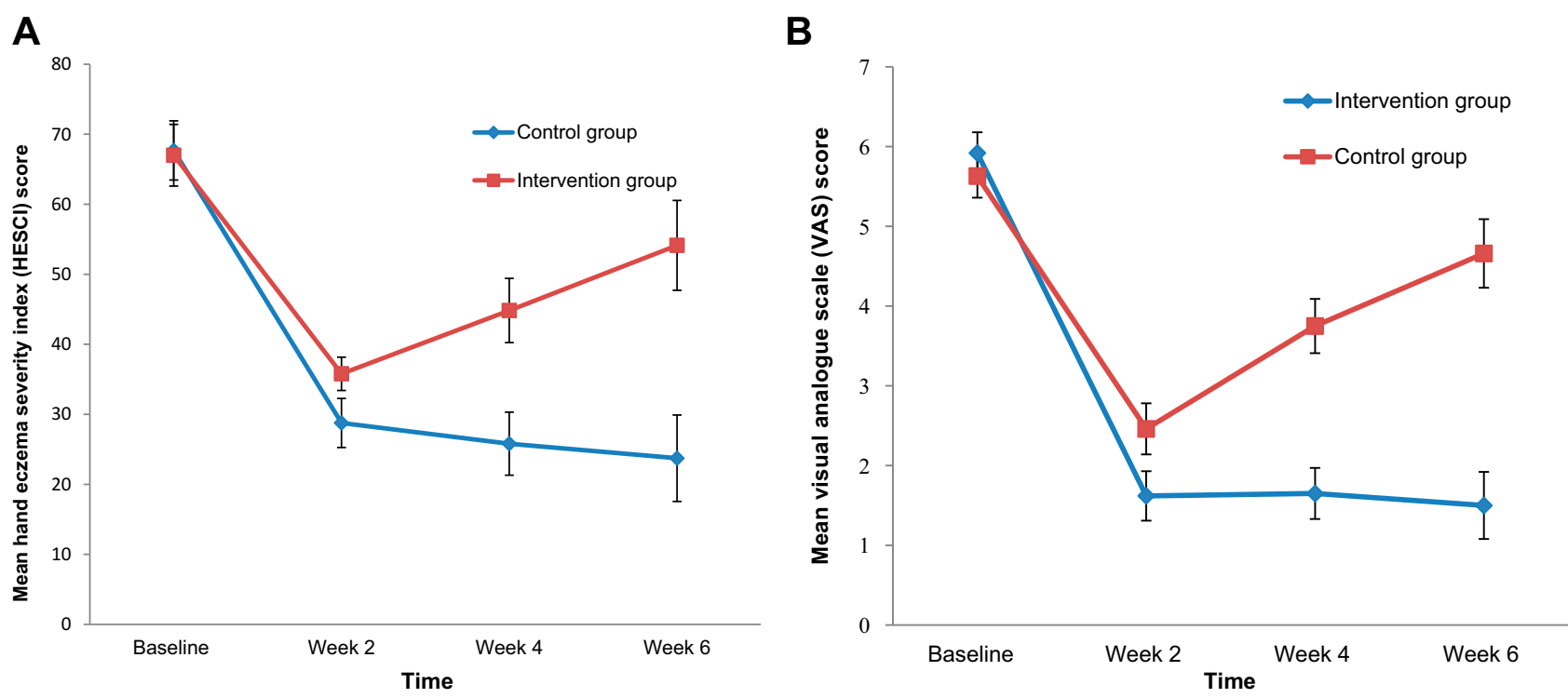

Figure 2 (A) Mean hand eczema severity index (HESI) score at different time points during study (P-value $<0.00 \mathrm{I})$. (B) Mean pruritus score based on the VAS scale at different time points during study (P-value<0.00I).

levels of pro-inflammatory biomarkers like IL-8. The elevated level of IL- 8 has been linked with pruritus in eczematous conditions and contributes to the pruritus sensations. ${ }^{43}$
Additionally, in murine models of contact hypersensitivity and neurogenic inflammation, the topical application of avenanthramides alleviated inflammatory responses and reduced

Table 4 Comparison of Prevalence Distribution of HECSI Severity Between 2 Groups at Different Time Points During the Study

\begin{tabular}{|c|c|c|c|c|c|c|}
\hline \multicolumn{2}{|c|}{ HECSI Severity } & \multirow{2}{*}{$\begin{array}{l}\text { Clear n (\%) } \\
0(0) \\
0(0)\end{array}$} & \multirow{2}{*}{$\begin{array}{l}\text { Almost Clear n (\%) } \\
0(0) \\
0(0)\end{array}$} & \multirow{2}{*}{$\begin{array}{l}\text { Moderate n (\%) } \\
5(19.2) \\
2(8.3)\end{array}$} & \multirow{2}{*}{$\begin{array}{l}\text { Severe n (\%) } \\
21(80.8) \\
22(91.7)\end{array}$} & \multirow{2}{*}{$\frac{P \text {-value }}{0.42}$} \\
\hline Baseline & $\begin{array}{l}\text { Intervention group } \\
\text { Control group }\end{array}$ & & & & & \\
\hline Week 2 & $\begin{array}{l}\text { Intervention group } \\
\text { Control group }\end{array}$ & $\begin{array}{l}0(0) \\
0(0)\end{array}$ & $\begin{array}{l}7(26.9) \\
3(12.5)\end{array}$ & $\begin{array}{l}14(53.8) \\
13(54.2)\end{array}$ & $\begin{array}{l}5(19.2) \\
8(33.3)\end{array}$ & 0.03 \\
\hline Week 4 & $\begin{array}{l}\text { Intervention group } \\
\text { Control group }\end{array}$ & $\begin{array}{l}0(0) \\
0(0)\end{array}$ & $\begin{array}{l}14(53.8) \\
3(12.5)\end{array}$ & $\begin{array}{l}6(23.1) \\
5(20.8)\end{array}$ & $\begin{array}{l}6(23.1) \\
16(66.7)\end{array}$ & 0.002 \\
\hline Week 6 & $\begin{array}{l}\text { Intervention group } \\
\text { Control group }\end{array}$ & $\begin{array}{l}7(26.9) \\
0(0)\end{array}$ & $\begin{array}{l}\mathrm{II}(42.3) \\
3(12.5)\end{array}$ & $\begin{array}{l}2(7.7) \\
6(25.0)\end{array}$ & $\begin{array}{l}6(23.1) \\
15(62.5)\end{array}$ & $<0.001$ \\
\hline
\end{tabular}

Notes: Hand eczema severity index (HECSI) severity was categorized as follows: clear, 0; almost clear, 1-16; moderate, 17-37; severe, 38-116; very severe, 2117.

Table 5 Comparison of Prevalence Distribution of VAS Severity Between 2 Groups at Different Time Points During the Study

\begin{tabular}{|c|c|c|c|c|c|c|}
\hline \multicolumn{2}{|c|}{ VAS Severity } & \multirow{3}{*}{$\begin{array}{l}\text { None n (\%) } \\
0(0) \\
0(0)\end{array}$} & \multirow{3}{*}{$\begin{array}{l}\text { Mild n (\%) } \\
I(3.8) \\
I(4.2)\end{array}$} & \multirow{3}{*}{$\begin{array}{l}\text { Moderate n (\%) } \\
17(65.4) \\
18(75.0)\end{array}$} & \multirow{3}{*}{$\begin{array}{l}\text { Severe n (\%) } \\
8(30.8) \\
5(20.8)\end{array}$} & \multirow{3}{*}{$\begin{array}{l}\text { P-value } \\
0.76\end{array}$} \\
\hline Baseline & Intervention group & & & & & \\
\hline & Control group & & & & & \\
\hline \multirow[t]{2}{*}{ Week 2} & Intervention group & $13(50.0)$ & $10(38.5)$ & $3(11.5)$ & $0(0)$ & 0.03 \\
\hline & Control group & $4(16.7)$ & $13(54.2)$ & $7(29.2)$ & $0(0)$ & \\
\hline \multirow[t]{2}{*}{ Week 4} & Intervention group & $12(46.2)$ & $8(30.8)$ & $6(23.1)$ & $0(0)$ & 0.006 \\
\hline & Control group & $2(8.3)$ & $8(33.3)$ & II (45.8) & $3(12.5)$ & \\
\hline \multirow[t]{2}{*}{ Week 6} & Intervention group & $7(36.9)$ & $14(53.8)$ & $5(19.2)$ & $0(0)$ & $<0.001$ \\
\hline & Control group & $\mathrm{I}(4.2)$ & $8(33.3)$ & $8(33.3)$ & $7(29.2)$ & \\
\hline
\end{tabular}

Notes: Visual analogue scale (VAS) severity was categorized as follows: mild pruritus (VAS<4.0), moderate pruritus (VAS 4.0-7.0), and severe pruritus (VAS>7.0). 
Table 6 Comparison of the Impact of Skin Disorder on Patients' Quality of Life Based on the DLQI Score in the Two Groups at Baseline and at the End of the Study Period (as Mean \pm SD)

\begin{tabular}{|l|l|l|l|}
\hline \multirow{2}{*}{ VAS Score } & \multicolumn{2}{|l|}{ Groups } & \multirow{2}{*}{ P-value } \\
\cline { 2 - 3 } & $\begin{array}{l}\text { Control } \\
\mathbf{( N = 2 4 )}\end{array}$ & $\begin{array}{l}\text { Intervention } \\
\mathbf{( N = 2 6 )}\end{array}$ & \\
\hline $\begin{array}{l}\text { Baseline } \\
\text { End of the study } \\
\text { (week 6) }\end{array}$ & $12.92 \pm 2.30$ & $12.88 \pm 2.67$ & 0.96 \\
$10.92 \pm 3.78$ & $5.58 \pm 5.35$ & $<0.001$ \\
\hline
\end{tabular}

Abbreviation: DLQI, Dermatology Life Quality Index.

pruritogen-induced scratching. ${ }^{13}$ Further, extracts of oats by inhibitory effects on biosynthesis and liberation of arachidonic acid from phospholipids in keratinocytes can decrease levels of the metabolites such as prostaglandins and leukotrienes which have possible roles in the development of chronic inflammatory skin disorders. ${ }^{44,45}$ Interestingly enough, due to chemical structure similarity of avenanthramides to the agents with anti-histamine activity, it is postulated that avenanthramides may also directly inhibit histamine signaling. ${ }^{13}$ Further, some experimental evidence shows avenanthramides can reduce the histamine release from mast cells stimulated by substance $\mathrm{P}{ }^{46}$ In concordance with this evidence, the results of one experimental study showed treatment with oatmeal extract oligomer in surviving human skin significantly reduced vasodilation and edema stimulated by the vasoactive intestinal peptide. ${ }^{14}$

Based on the mechanism of action, in recent years, clinical efficacy and safety of topical formulations of colloidal oatmeal for the treatment various inflammatory skin conditions have been investigated. In this regard, Nebus and colleagues in their study found subjects with mild to moderate atopic dermatitis who used an oatmeal-based skincare regimen adjunct to their normal topical medications had significant improvement on eczema severity and itch sensation at 2 weeks after treatment. ${ }^{47}$ Grimalt and colleagues' study also showed compared to the control group, the application of emollient containing oat extract significantly reduced the use of topical corticosteroids in infants with moderate to severe atopic dermatitis. ${ }^{48}$ In line with this, in one double-blind, randomized, activecontrolled study, Lisante et al recently reported over-thecounter $1 \%$ colloidal oatmeal cream is as effective as a prescription barrier cream for the symptomatic treatment mild-to-moderate atopic dermatitis in children. ${ }^{10}$ In contrast to these findings, one French prospective study found oat sensitization is higher than expected in children with atopic dermatitis. ${ }^{49}$ These discrepancies can be partially justified by the methodological flaws in French study which used oat pollen for skin prick tests and IgE testing. Oat pollen is unlikely to contain the same proteins found in colloidal oatmeal.

In vivo in SLS irritation model in human, potential efficacy of topically applied oatmeal extracts have been also investigated by Vié et al. Results of this study showed oatmeal extracts by anti-inflammatory effects on skin inflammation are able to modulate SLS induced skin irritation. ${ }^{50}$ Clinical benefits of colloidal oatmeal lotion application on controlling cutaneous eruption induced by epidermal growth factor receptor and multiple tyrosinekinase inhibitors were also observed in Alexandrescu et al's study. It is postulated that the effectiveness of colloidal oatmeal in this setting also attributed to its antiinflammatory mechanisms. ${ }^{51}$ Oatmeal baths as adjuvant treatment are also considered as an effective therapeutic modality in the management of patients with erythrodermic psoriasis. ${ }^{52}$

Therefore, there is promising evidence with the use of topical oatmeal compounds in the management of inflammation and itch responses associated with diverse dermatologic conditions. One clinical aspect that has made the natural products such as, colloidal oatmeal as an attractive therapeutic modality in the management of HE and other dermatological disorders is their excellent safety and tolerability compared to conventional medications during longterm treatment. In this respect, results of one open-labeled, post-marketing feedback trial showed in addition to its significant anti-itching and moisturizing properties against varieties of dry skin conditions, oatmeal moisturizer is well tolerated in the patients of all age groups. ${ }^{53}$ In similar findings, results of another study demonstrated that colloidal oatmeal is a safe ingredient in personal care products (creams, cleansers, lotions) and irritation and allergenic potential of the study materials were low. ${ }^{54}$ Therefore, this margin of safety and excellent efficacy makes colloidal oatmeal as an attractive therapeutic option in the management of chronic HE.

Despite the novelty of the findings, the results of the current study should be interpreted cautiously because it suffers from a number of limitations. The first limitation of this study is the relatively small number of subjects and short duration of follow up that can affect the generalization of our results. More studies with larger sample sizes and longer follow-up are warranted to validate the findings reported here. The second limitation of the 
present study is that we used colloidal oatmeal as adjutant therapy to topical corticosteroids in the management of HE, so its therapeutic effects as monotherapy on clinical outcomes need to be addressed in future studies. Additionally, we investigate the effectiveness of colloidal oatmeal only in patients with irritant HE. Additional trials are needed to evaluate the effectiveness of colloidal oatmeal for the treatment of other types of HE.

\section{Conclusion}

In conclusion, our findings demonstrate that colloidal oatmeal, a natural product with proven barrier protection, moisturization, anti-inflammatory, and soothing properties, can have beneficial effects as an adjunct therapy in the management of inflammatory skin diseases, such as irritant HE.

\section{Data Sharing}

The datasets used and/or analyzed during the current study are available from the corresponding author on reasonable request up to 2 years after publication.

\section{Acknowledgments}

This study was supported by the Vice-Chancellor of Research and Technology of Hamadan University of Medical Sciences, Hamadan, Iran (No: 9711026598). The authors thank all patients for helping and participating in the study.

\section{Disclosure}

The authors report no conflicts of interest in this work.

\section{References}

1. Warshaw EM, Ahmed RL, Belsito DV, et al. Contact dermatitis of the hands: cross-sectional analyses of North American contact dermatitis group data, 1994-2004. J Am Acad Dermatol. 2007;57(2):301-314. doi:10.1016/j.jaad.2007.04.016

2. Lakshmi C, Srinivas C. Hand eczema: an update. Indian J Dermatol Venereol Leprol. 2012;78(5):569. doi:10.4103/0378-6323.100547

3. Meding B, Wrangsjö K, Järvholm B. Fifteen-year follow-up of hand eczema: persistence and consequences. Br J Dermatol. 2005;152 (5):975-980. doi:10.1111/bjd.2005.152.issue-5

4. Sehgal VN, Srivastava G, Aggarwal AK, Sharma AD. Hand dermatitis/eczema: current management strategy. J Dermatol. 2010;37 (7):593-610. doi:10.1111/jde.2010.37.issue-7

5. Eberting C. Irritant contact dermatitis: mechanisms to repair. J Clin Exp Dermatol Res. 2014;5(246):2. doi:10.4172/2155-9554.1000246

6. Spiekstra S, Toebak M, Sampat-sardjoepersad S, et al. Induction of cytokine (interleukin- $1 \alpha$ and tumor necrosis factor- $\alpha$ ) and chemokine (CCL20, CCL27, and CXCL8) alarm signals after allergen and irritant exposure. Exp Dermatol. 2005;14(2):109-116. doi:10.1111/j.09066705.2005.00226.x
7. Wilmer JL, Burleson FG, Kayama F, Kanno J, Luster MI. Cytokine induction in human epidermal keratinocytes exposed to contact irritants and its relation to chemical-induced inflammation in mouse skin. J Investig Dermatol. 1994;102(6):915-922. doi:10.1111/15231747.ep12383512

8. Bissonnette R, Diepgen T, Elsner $\mathrm{P}$, et al. Redefining treatment options in chronic hand eczema (CHE). J Eur Acad Dermatol Venereol. 2010;24:1-20. doi:10.1111/jdv.2010.24.issue-s3

9. Kurtz ES, Wallo W. Colloidal oatmeal: history, chemistry and clinical properties. J Drugs Dermatol. 2007;6(2):167-170.

10. Lisante TA, Nuñez C, Zhang P. Efficacy and safety of an over-thecounter $1 \%$ colloidal oatmeal cream in the management of mild to moderate atopic dermatitis in children: a double-blind, randomized, active-controlled study. J Dermatolog Treat. 2017;28(7):659-667. doi:10.1080/09546634.2017.1303569

11. Michelle Garay M, Judith Nebus M, Menas Kizoulis B. Antiinflammatory activities of colloidal oatmeal (Avena sativa) contribute to the effectiveness of oats in treatment of itch associated with dry, irritated skin. J Drugs Dermatol. 2015;14(1):43-48.

12. Fowler JJ, Woolery-lloyd H, Waldorf H, Saini R. Innovations in natural ingredients and their use in skin care. $J$ Drugs Dermatol. 2010;9(6 Suppl):S72-S81; quiz s2-s3.

13. Sur R, Nigam A, Grote D, Liebel F, Southall MD. Avenanthramides, polyphenols from oats, exhibit anti-inflammatory and anti-itch activity. Arch Dermatol Res. 2008;300(10):569. doi:10.1007/ s00403-008-0858-x

14. Boisnic S, Branchet-gumila M, Coutanceau C. Inhibitory effect of oatmeal extract oligomer on vasoactive intestinal peptide-induced inflammation in surviving human skin. Int J Tissue React. 2003;25 (2):41-46.

15. Lin T-K, Zhong L, Santiago JL. Anti-inflammatory and skin barrier repair effects of topical application of some plant oils. Int J Mol Sci. 2018;19(1):70. doi:10.3390/ijms19010070

16. Held E, Skoet R, Johansen J, Agner T. The hand eczema severity index (HECSI): a scoring system for clinical assessment of hand eczema. A study of inter-and intraobserver reliability. Br J Dermatol. 2005;152 (2):302-307. doi:10.1111/j.1365-2133.2004.06305.x

17. Pazyar N, Yaghoobi R, Kazerouni A, Feily A. Oatmeal in dermatology: a brief review. Indian J Dermatol Venereol Leprol. 2012;78 (2):142. doi:10.4103/0378-6323.93629

18. Oosterhaven J, Schuttelaar M. Responsiveness and interpretability of the Hand Eczema Severity Index. Br J Dermatol. 2019. doi:10.1111/ bjd. 18295

19. Reich A, Heisig M, Phan NQ, et al. Visual analogue scale: evaluation of the instrument for the assessment of pruritus. Acta Derm Venereol. 2012;92(5):497-501. doi:10.2340/00015555-1265

20. Aghaei S, Sodaifi M, Jafari P, Mazharinia N, Finlay AY. DLQI scores in vitiligo: reliability and validity of the Persian version. $B M C$ Dermatol. 2004;4(1):8. doi:10.1186/1471-5945-4-8

21. Finlay AY, Khan G. Dermatology Life Quality Index (DLQI) - a simple practical measure for routine clinical use. Clin Exp Dermatol. 1994;19(3):210-216. doi:10.1111/ced.1994.19.issue-3

22. Thyssen JP, Johansen JD, Linneberg A, Menné T. The epidemiology of hand eczema in the general population-prevalence and main findings. Contact Dermatitis. 2010;62(2):75-87. doi:10.1111/ cod.2010.62.issue-2

23. Smith H, Basketter D, McFadden J. Irritant dermatitis, irritancy and its role in allergic contact dermatitis. Clin Exp Dermatol. 2002;27 (2):138-146. doi:10.1046/j.1365-2230.2002.00997.x

24. Jakasa I, Thyssen JP, Kezic S. The role of skin barrier in occupational contact dermatitis. Exp Dermatol. 2018;27(8):909-914. doi:10.1111/ exd.2018.27.issue-8

25. Yoshiike T, Aikawa Y, Sindhvananda J, et al. Skin barrier defect in atopic dermatitis: increased permeability of the stratum corneum using dimethyl sulfoxide and theophylline. J Dermatol Sci. 1993;5 (2):92-96. doi:10.1016/0923-1811(93)90076-2 
26. Nebus J, Schmalenberg K, Wallo W. The effectiveness of an oatmeal lotion in improving and maintaining barrier function and moisture levels of moderate to severe xerosis. J Am Acad Dermatol. 2009;60(3).

27. Vaughn AR, Clark AK, Sivamani RK, Shi VY. Natural oils for skin-barrier repair: ancient compounds now backed by modern science. Am J Clin Dermatol. 2018;19(1):103-117. doi:10.1007/ s40257-017-0301-1

28. Michelle Garay M. Colloidal oatmeal (Avena Sativa) improves skin barrier through multi-therapy activity. J Drugs Dermatol. 2016;15 (6):684-690.

29. Vávrová K, Kováčik A, Opálka L. Ceramides in the skin barrier. Eur Pharm J. 2017;64(2):28-35. doi:10.1515/afpuc-2017-0004

30. Di Nardo A, Sugino K, Wertz P, Ademola J, Maibach H. Sodium lauryl sulfate (SLS) induced irritant contact dermatitis: a correlation study between ceramides and in vivo parameters of irritation. Contact Dermatitis. 1996;35(2):86-91. doi:10.1111/j.1600-0536.1996. tb02296.x

31. Hansen HS, Jensen B. Essential function of linoleic acid esterified in acylglucosylceramide and acylceramide in maintaining the epidermal water permeability barrier. Evidence from feeding studies with oleate, linoleate, arachidonate, columbinate and $\alpha$-linolenate. Biochim Biophys Acta Lipids Lipid Metab. 1985;834(3):357-363. doi:10.1016/0005-2760(85)90009-8

32. Tessema EN, Gebre-mariam T, Lange S, Dobner B, Neubert RH Potential application of oat-derived ceramides in improving skin barrier function: part 1 . Isolation and structural characterization. J Chromatogr B. 2017;1065:87-95. doi:10.1016/j. jchromb.2017.09.029

33. Chon SH, Tannahill R, Yao X, Southall MD, Pappas A. Keratinocyte differentiation and upregulation of ceramide synthesis induced by an oat lipid extract via the activation of PPAR pathways. Exp Dermatol. 2015;24(4):290-295. doi:10.1111/exd.12658

34. Ali SM, Yosipovitch G. Skin pH: from basic science to basic skin care. Acta Derm Venereol. 2013;93(3):261-269. doi:10.2340/ 00015555-1531

35. Lee HY, Stieger M, Yawalkar N, Kakeda M. Cytokines and chemokines in irritant contact dermatitis. Mediators Inflamm. 2013;2013.

36. Uggeldahl P-E, Kero M, Ulshagen K, Solberg V. Comparative effect of desonide cream $0.1 \%$ and $0.05 \%$ in patients with hand eczema. Curr Ther Res. 1986;40(5):969-973.

37. Gupta AK, Shear NH, Lester RS, Baxter ML, Sauder DN. Betamethasone dipropionate polyacrylic film-forming lotion in the treatment of hand dermatitis. Int J Dermatol. 1993;32(11):828-829. doi:10.1111/ijd.1993.32.issue-11

38. Bleeker J, Anagrius C, Iversen N, Stenberg B, Valentin KC. Doubleblind comparative study of Corticoderm ${ }^{\circledR}$ cream+ Unguentum Merck $^{\circledR}$ and Betnovate ${ }^{\circledR}$ cream+ Unguentum Merck ${ }^{\circledR}$ in hand dermatitis. $J$ Dermatolog Treat. 1989;1(2):87-90. doi:10.3109/ 09546638909086701

39. Hengge UR, Ruzicka T, Schwartz RA, Cork MJ. Adverse effects of topical glucocorticosteroids. J Am Acad Dermatol. 2006;54(1):1-15. doi:10.1016/j.jaad.2005.01.010

40. Dimberg LH, Theander O, Lingnert H. Avenanthramides-a group of phenolic antioxidants in oats. Cereal Chem. 1993;70:637.
41. Emmons CL, Peterson DM, Paul GL. Antioxidant capacity of oat (Avena sativa L.) extracts. 2. In vitro antioxidant activity and contents of phenolic and tocol antioxidants. J Agric Food Chem. 1999;47 (12):4894-4898. doi:10.1021/jf990530i

42. Guo W, Wise ML, Collins FW, Meydani M. Avenanthramides, polyphenols from oats, inhibit IL-1 $\beta$-induced NF- $\kappa \mathrm{B}$ activation in endothelial cells. Free Radic Biol Med. 2008;44(3):415-429. doi:10.1016/j.freeradbiomed.2007.10.036

43. Lippert U, Hoer A, Möller A, Ramboer I, Cremer B, Henz B. Role of antigen-induced cytokine release in atopic pruritus. Int Arch Allergy Immunol. 1998;116(1):36-39. doi:10.1159/000023922

44. Aries M-F, Vaissiere C, Pinelli E, Pipy B, Charveron M. Avena rhealba ${ }^{\circledR}$ inhibits A23187-stimulated arachidonic acid mobilization, eicosanoid release, and cPLA2 expression in human keratinocytes: potential in cutaneous inflammatory disorders. Biol Pharm Bull. 2005;28(4):601-606. doi:10.1248/bpb.28.601

45. Saeed SA, Butt NM, McDonald-Gibson WJ, Collier HO. Inhibitors of prostaglandin biosynthesis in extracts of oat (Aveena sativa) seeds Biochem Soc Trans. 1981;9(444):144. doi:10.1042/bst0090444

46. Cerio R, Dohil M, Jeanine D, Magina S, Mahe E, Stratigos AJ. Mechanism of action and clinical benefits of colloidal oatmeal for dermatologic practice. J Drugs Dermatol. 2010;9(9):1116-1120.

47. Nebus J, Nystrand G, Fowler J, Wallo W. editors. A daily oat-based skin care regimen for atopic skin. Journal of the American Academy of Dermatology; 2009. Mosby-Elsevier 360 Park Avenue South, New York, NY 10010-1710 USA

48. Grimalt R, Mengeaud V, Cambazard F. The steroid-sparing effect of an emollient therapy in infants with atopic dermatitis: a randomized controlled study. Dermatology. 2007;214(1):61-67. doi:10.1159/ 000096915

49. Boussault P, Léauté-labrèze C, Saubusse E, et al. Oat sensitization in children with atopic dermatitis: prevalence, risks and associated factors. Allergy. 2007;62(11):1251-1256. doi:10.1111/j.13989995.2007.01527.x

50. Vie K, Cours-darne S, Vienne M, Boyer F, Fabre B, Dupuy P. Modulating effects of oatmeal extracts in the sodium lauryl sulfate skin irritancy model. Skin Pharmacol Physiol. 2002;15(2):120-124. doi:10.1159/000049399

51. Alexandrescu D, Vaillant J, Dasanu C. Effect of treatment with a colloidal oatmeal lotion on the acneform eruption induced by epidermal growth factor receptor and multiple tyrosine-kinase inhibitors. Clin Exp Dermatol. 2007;32(1):71-74.

52. Robinson A, Van Voorhees AS, Hsu S, et al. Treatment of pustular psoriasis: from the Medical Board of the National Psoriasis Foundation. $J$ Am Acad Dermatol. 2012;67(2):279-288. doi:10.1016/j.jaad.2011.01.032

53. Narayanan V, Ganjod A, Kandhe G. Efficacy and tolerability of an oatmeal moisturizer containing colloidal oatmeal for dry skin conditions: a post marketing study. Indian $J$ Clin Pract. 2016;27:1117-1122

54. Criquet M, Roure R, Dayan L, Nollent V, Bertin C. Safety and efficacy of personal care products containing colloidal oatmeal. Clin Cosmet Investig Dermatol. 2012;5:183. doi:10.2147/CCID.S31375
Clinical, Cosmetic and Investigational Dermatology is an international, peer-reviewed, open access, online journal that focuses on the latest clinical and experimental research in all aspects of skin disease and cosmetic interventions. This journal is indexed on CAS
The manuscript management system is completely online and includes a very quick and fair peer-review system, which is all easy to use. Visit http://www.dovepress.com/testimonials.php to read real quotes from published authors. 